\title{
Introduction
}





\title{
Introduction
}

\section{Public Service Media Initiatives in the Global South}

\author{
Anis Rahman* \\ Simon Fraser University, Canada
}

The past two decades have seen a significant practical and scholarly interest in the development of public service broadcasting (henceforth, PSB) as the meaning and narrative of both 'public service' and 'broadcasting' have been challenged, sometimes extended, largely transformed, and continually renegotiated in response to changing circumstances. Defining PSB has always been a daunting task and is arguably even more difficult today given that distinctions between public service broadcasting, state-administered broadcasting, and often, commercial broadcasting are increasingly blurred.

UNESCO (2014) offered a simple definition, "Public Service Broadcasting (PSB) is broadcasting made, financed, and controlled by the public, for the public. It is neither commercial nor state-owned, free from political interference and pressure from commercial forces." A mature model of PSB, in this definition, implies an autonomous organization that is supported by the state but controlled and managed as an independent public corporation, funded by public money either via licensing fees or via taxes (e.g. CBC in Canada). PSB is often equated with public broadcasting in the USA (independently owned, financed, and managed by the public via donations, e.g. Pacifica radio in the US) and elsewhere conflated with state broadcasting services (entirely owned and controlled by the state, e.g. CCTV in China). In this volume on PSB in the Global South we adopt an inclusive vision of media as public enterprises, which brings state-administered and public service broadcasting (and their services provided on nonbroadcast platforms), community broadcasting, grassroots media, and civic journalism on public issues together under a broad umbrella that we characterize as Public Service Media (PSM).

Academic study about PSB, and activism for this, are not new. A comprehensive literature and diverse case studies have been produced over the decades since the early $20^{\text {th }}$ century. But here we especially note the significant contributions made in the $21^{\text {st }}$ century by the RIPE initiative: Re-Visionary Interpretations of the Public Enterprise (http://ripeat.org/). Beginning in 2000, hundreds of media scholars from dozens of countries around the world have been working to investigate, clarify and chart the variety of approaches to PSM, similarities across contexts, and innovations. The series of RIPE Readers published by NORDICOM since 2003 are now available as free downloads (PDF format) on the publisher's website. Some have been particularly important for scholarship and activism in the Global South (e.g. Lowe \& Yamamoto, 2016; Lowe \& Martin, 2014; Lowe \& Steemers, 2012; Lowe \& Bardoel, 2007). Media scholars and activists are increasingly invested in rethinking, reassessing, and internationalizing PSM discourses (e.g. Horowitz \& Nieminen, 2016; Horowitz \& Car, 2015; Abbott, 2016). 
A vibrant volume of research reports, columns, and blogs on a diverse PSB and PSM-related issues are being produced and published online (e.g. see, mediapowermonitor.com, Global PSM Experts Networks Facebook Group, Public Media Alliance updates, and \#publicbroadcasting or \#publicservicemedia). Recent topics of discussion range from debate on the future of the $\mathrm{BBC}$, to jobs cuts at $\mathrm{CBC}$ in Canada, to the mobile strategy of PBS News Hour in the USA, to heightened political control of Polish public media, problems of public broadcasting in Bosnia and Herzegovina, the independence of the Croatian public broadcaster, and the rise of a new PSB network in Latin America.

While the fora of research contributing to this increase in global awareness and visibility of PSM, aside few exceptional work (e.g. Tambini, 2015), largely showcases institutional models and practices of PSM that originated in and are characteristic of in the Global North. That has been the essential focus steering the agenda on research about the present and for future development. Indeed, the dominating epistemology of PSM is deeply rooted in the northern European context and traditions of social democracy. The orientations and practices elsewhere have been under-researched and even sometimes ignored. Given that stateadministered type media have been historically dominant in the Global South, the struggles to establish public media and to open new opportunities for developing public values in the vast and highly diverse terrain of the Global South is a pressing contemporary challenge for media scholarship. Linguistic barriers and lack of support for research make research more difficult for media scholars here.

This volume brings together insights from a cohort of emerging scholars and practitioners from Bangladesh, Malaysia, Indonesia, Mexico, Morocco, Taiwan, and South Africa, all of whom participated in the RIPE@2014 Conference in Tokyo and agreed to delve deeper into the national and regional aspects of publicly funded media initiatives in the Global South. ${ }^{1}$ Here we employ the term public media initiatives as an inclusive phrase that connotes the public service values present in all publicly funded media enterprises, including stateadministered and public service broadcasting, community broadcasting, and a varieties of emerging civic media practices. We do not intend to flatten all PSM ventures into a homogenous category, but on the contrary employ the term public media initiatives as a contextual, relative, and plural ontology, in which the degree of public service and nature of ownership may vary among enterprises and across regions.

The authors of this volume primarily explore answers to two key questions. First, what are the common dilemmas and biggest hurdles for developing public service media in the Global

1 The United Nation Development Program (UNDP, 2013) defines the term "South" or "Global South" as "developing countries, which are located primarily in the Southern Hemisphere." There are plenty arguments against such simplistic categorization of the North-South divide (see, Global South Studies Center, 2015). Obviously, Australia and New Zealand are located in the South Hemisphere but they are not developing countries. Same argument can be applied to Malaysia, Taiwan, or Argentina. Numerous attempts have been made to make classification of the global South and the global North objective (such as applying 1980s Brandt Line - latitude 30 North, or classifying with recent UNDP's Human Development Index), but any blanket terms would prove to be inadequate or inaccurate to capture global diversity, historical complexity, and increasing interconnectivity. Some acknowledge that the term Global South is not perfect, but it is favorable than its predecessors, "Third World” or "Developing World” (see, Rigg, 2007). Agreeing with this view, and acknowledging the imperfection of the terminology, we refer to the term the Global South not necessarily as a fixed geographical or economic entity but as a dynamic political and cultural imagination that connects and reflects the realities of the countries we explore in this project. 
South, and what interventions may help advance the cause in a non-Western and emerging contexts? Here we are especially interested to understand what we can learn from each other. Second, what is being done already, not only formal institutional terms but also especially in practice? This volume does not claim to represent a comprehensive comparative view of all public media initiatives in the Global South, but rather offers a selective collection of case studies that reveal overlapping commonalities as well as dissimilarities across the treated cases - which are diverse enough to suggest an important range of shared aspirations and also challenges. Our goal is to support RIPE's ongoing efforts to develop dialogue, research and advocacy in a complex and constantly evolving network of communication scholars and practitioners. The motivation is to encourage and promote mutual learning that can facilitate the development of public service media in the Global South.

\section{Research Methodology}

The Mapping Digital Media (MDM) Project conducted by the Open Society Foundations (2013) provides a useful research template for this project. We adopt several indicators from the MDM project that fit within the more targeted and also more limited scope of our project, while introducing some indicators of our own (see Annex at the end of this chapter). In addition to bringing in secondary data from existing local and regional sources, the authors enrich their insights by employing small-scale in-depth interviews with key-informants engaged with PSM development in each case, and drawing on especially relevant archival research. The scope and depth of research vary across chapters, but each contributor provides a brief overview of one region and investigates a case country to exemplify. They collectively focus on state-administered/public service broadcasters to address common issues and concerns, including public service provision, ownership, funding models, the impact of politicization, commercialization in journalism, the potentials of online, and communitybased initiatives, with a shared goal of fostering alternative avenues for the development of media policy that can facilitate building public service media in broadcasting and online.

\section{Chapter Summaries}

The chapters of this volume are organized in the order they were proposed. The first chapter provides a synoptic account of how a state-administered broadcaster maintains its power in the face of changing media landscapes. While the chapter is specific to Bangladesh, it shows that South Asian countries contain a diverse array of media systems with varied degrees of public service mandates and ongoing reforms. In many parts of the Global South (especially South Asia, Southern Africa) the colonial public media became state administered media after independence. The author argues that as a postcolonial media institution, the Bangladeshi state broadcaster (BTV) is deeply submerged in political subservience but also projects an image as being a public media provider in its promotion of Bangladeshi culture and heritage. The author stresses that BTV needs a complete overhaul to function as a proper independent public media organization. But the case begs the question as to whether institutional and policy reforms are enough to transform a state-broadcaster into a functioning PSM if there is no supportive political environment and economic incentive? 
Regardless of the political systems, be they more or less democratic or authoritarian, the ruling class in much of the Global South is willing to reform state-administered broadcasting systems only up to a certain extent - only so far as doing so doesn't compromise or threaten to destabilize the status quo, which is to say the power of governors to control media content when and as they see this as a necessity for various reasons. This message is made quite clear in chapter 2 where Bouziane Zaid argues that over the last decade, the regulatory body in Morocco (HACA) enabled an apparent transformation of the state-owned broadcaster. The ostensible goal was to encourage an autonomous public enterprise. But in fact, the government has retained control through repressive legal codes. Despite the presence of supportive legal provisions, as Zaid identifies, PSB in the Middle East and North Africa (MENA) remains a "pseudo public system" in a kind of game played by "competitive authoritarian regimes." Although the legal frameworks and institutional structures are in place, the political culture in Morocco (and elsewhere), makes it impossible to materialize public service practices as genuinely independent, properly critical and purely produced in the public interest. The mission to establish PSB is, therefore, still in an embryonic stage in Morocco - and the same goes for the other more liberal nation-states in MENA, e.g. Jordan, Tunisia, and Lebanon. Zaid's chapter is especially important in demonstrating how and why this is characteristic.

A different category of PSM initiatives is explored in chapter 3. Here José Antonio Brambila explores a range of PSM-initiatives in an aspiring cultural environment, but these initiatives, as he argues, must survive alongside a highly concentrated and hegemonic commercial media system. The author entertains us with cautious optimism that with complex varieties of PSM under development (e.g. nearly 596 stations and channels), Mexico is stepping towards the right direction to foster a functioning PSM system, but he acknowledges there is a long way still to go. With a high concentration of commercial media in Mexico and elsewhere in Latin America, combined with lack of editorial independence and high degree of government control and interference in state or public organizations, there is very little room for more genuine public media initiatives to grow. Brambila makes the important point that public service models do not simplistically 'flow' from the Global North to the Global South. Quiet the contrary, PSM must be adapted (not adopted), and this suggests it can only emerge in alignment with a very complex mix of locales with distinctive situations, values, ideas, experiences, and necessities, all of which ultimately shape both the nature of the journey and the likely destination. Brambila is hopeful that the novel institutional reforms underway in many countries in this region, and encouraging incentives to support the development of existing institutions in Brazil, Chile, Colombia, and Mexico, may see a transformation in the region as a promising socio-cultural environment for genuine public service media.

James Curran (2002) noted that PSB does not mean only public broadcasting because a commercial media outlet can serve public service role if it complies with mandates and regulations to fulfill public objectives (as for example with Sweden's TV4 and Finland's MTV). Instead of dealing with the state-broadcaster, Roslina Abdul Latif takes a different tact in Chapter 4 to explore whether a PSB model of the independent editorial process can be exercised in Malaysian commercial media newsrooms. Badrul Redzuan Abu Hassan joins her in the research by adding insights from PSM practices in neighboring Indonesia. The authors provide an overview of media systems and regulatory regimes in each country, juxtapose the findings from both countries, and conclude that newsroom decision-making processes would be less biased if truly independent regulatory bodies set the rules and enforce regulations. 
These considerations beg the question as to whether it is possible for a state to develop a new PSB organization without controlling it. Although the term Global South does not fit very well with the geographic and economic positions of Taiwan, it is appropriate to historic conditions in the relations between the state and media, which have been highly politicized. In the past decades or so, Taiwan has made a promising effort to establish a public service system. Chapter 5 by Hamilton Cheng and Yang Lee shows that it is possible to have a state-supported media sector without turning it into a state-administered media operation, and that achieving this depends strongly on popular support that is both deep and sustained.

PSB in Taiwan was born as a government initiated media development project to secure and reinforces national identity in the conflicted context of relations with the People's Republic of China. With ample funding from the government, Taiwanese PSB was re-structured on the basis of technological advancement and institutional reforms. Surrounded by strong media markets (e.g. Korea, Japan, Hong Kong, and mainland China) and troubled by "foreign cultures" (notably Korean Wave), the government equipped the media industry with its own public service sector. Despite considerable resources and generally widespread support, the work is far from complete and this case illustrates why it is important for scholars and policymakers to exercise both caution and patience when analyzing a situation. The Taiwanese case illustrates a complex and dynamic process that can require decades to unfold, and that can only succeed when there is sufficient grassroots support to force the issue when push comes to shove - as it inevitably will because media are clearly political institutions.

The last chapter investigates the political, regulatory, and technological implications of the digitization of PSB in South Africa. Author Nomonde Gongxeka walks us through a maze of post-apartheid institutional reforms that enabled a public service mandate to emerge, and focuses on the institutional struggles of the South African Broadcasting Corporation (SABC) as it is transforming from PSB to PSM. The analysis reveals how a high dependency on commercial funding coupled with increasing political insecurity and aggravated by rapid technological changes now pose enormous difficulties in maintaining the historic and now threatened editorial independence of SABC as a public media enterprise. While this picture looks all too familiar given the characteristic and chronic ills of state-broadcasting elsewhere, there is reason to be hopeful about SABC's role as a public broadcaster, given its core strengths in popular programming contents, producing locally, and delivering to a multitude of linguistic and ethnic audiences.

\section{What can we learn from each other?}

The complex architecture and perhaps dizzying varieties of PSM structures, organizations and practices in the Global South cannot be captured in one volume and should not be subjected to simplistic reductionism. That said, and even within the limited scope of research for this project, the chapters of this volume reveal a great many similarities as well as significant dissimilarities shared across countries and regions. The similarities are mostly political, economic, and historical, and tied to postcolonial structures and contemporary forces associated with global capitalism. The dissimilarities are largely institutional and cultural, and keyed to the geographic, linguistic, socio-cultural and conditional specificities of each region and nation-state. Some observations can be highlighted. 


\section{First, public service and state-administered broadcasters are remarkably resilient against odds}

The public service and state-administered broadcasters in many countries in the Global South are not dying. Contrary to some apocalyptic predictions, state-administered broadcasters are remarkably resilient against versatile challenges, which certainly include shifting audience habits, evolving technological platforms, competition with growing private media powers, and, most significantly, being forced to defend and also compromise public service values in the face of growing political, economic, and ideological pressures, instabilities, and insecurities. In fact, this is not unusual or unique. Even in Western Europe, public service television is stubbornly successful in many countries, and they are surviving against the odds. Des Freedman (2015) argues that changes in viewing and consumption habits are often overstated. Despite forecasts that PSB would lose viewers and interest in the digital transition and to social media, public service channels in the UK (i.e. BBC, ITV, Channel 4, and Five) still claim the largest audience shares. These channels have invested significantly in producing original contents to stay relevant to a range of audiences across different demographics and platforms. Many state-administred broadcasters in the Global South are catching up with such trends.

\section{Second, political interference is the biggest obstacle for a PSM both to develop and to function properly}

Political influence and resulting lack of independence appears to be the biggest hurdle in most cases, and is especially problematic in contexts where there is a history of state broadcasting with characteristic high political control over content as well as operations. The country case studies of Bangladesh, Morocco, Mexico, Indonesia, and South Africa demonstrate how the state-administered broadcasters in these countries are struggling to build and to maintain editorial autonomy in the face of strong and persistent, if sometimes subtle, political meddling. Again, this is a global trend, and by no means confined to the Global South. The BBC is continually challenged with the need to fend of political intervention of various types and to differing extents, and in much of west Europe today historical PSB institutions are under fierce political attacks that are apparently motivated by neoliberal constituencies. PSB in many central and eastern European countries is challenged by overt political efforts to exert renewed state control over news and programming operations.

Even private television channels are not immune from political influence, however much their advocates insist otherwise. Indeed, the autonomy of many state-administered broadcasters in the Global South is caught in the complex crosscurrents of a colonial heritage, the postcolonial quests for nation building, and the governments' growing anxiety to lose its grip over the informal economy of public broadcasting arises from the neoliberal restructuring of global communication. ${ }^{2}$ The governments are reluctant to grant autonomy also because of the fear that if media are truly independent they would become critical of the state. This is why ruling parties are typically so inclined to ensure regulations that bestow on them relatively

2 I have argued elsewhere that if we want to understand why state broadcasters in the Global South did not emerge as a full-fledged PSB, as in many European countries, we have to see the historic circumstances in which the state broadcasters in many postcolonial nation-states came into being (see, Rahman, 2014). 
unhindered power to appoint the managers and set the resource limits on 'public' broadcasters. The organizational hierarchy for many broadcasting institutions makes sure that the chain of command extends all the way to the newsroom, and that oversight remains continually vigilant. Taiwan is an exceptional case here, against demonstrating important differences. Cheng and Lee inform us that Taiwan's PSB Employees Union can nominate its own candidate to sit on the Board of Governance of PTS.

\section{Third, the existing PSBs are financially broke and the new PSM initiatives seem be better off when they are self-funded}

The lack of funding, and ensuing dependency on commercials, is an endemic challenge for the development of a fully functional public media. Governments have increased funding in most cases, however not to an extent that helped much to meet the growing costs and expenditures caused by digitalization and inflation. Public service media initiatives in Mexico competing with one of most concentrated commercial media systems in Latin America. Although the public media in Mexico is subsidized in principle, in practice they remain vulnerable to budgetary manipulations. Bangladesh Television (BTV) strives to maintain its prominence by charging the highest rate for television advertising during the primetime news program, yet it suffers incessant loses. The news and current affairs programming in South African Broadcasting Corporation (SABC), on the contrary, are barred from receiving any form of sponsorship from commercial entities and the growth of political influence on editorial work is significant, in part by controlling the purse strings. Which way, then, to survive?

High amounts of advertising funding does not guarantee the political freedom of a state broadcaster. That is clear. With all the state's support and heavily funded by advertising, China Central Television (CCTV) remains the most tightly controlled television station in the country (Zhao, 2004, p. 183). On a relevant note, Gregory Ferrell Lowe and Christian Berg (2013) argue from an European perspective that debate about funding public broadcasting is not only about funding; but about wider issues only partly rooted in the current economic malaise. The global financial crisis increases the financial insecurity of PSB but also presents an opportunity for restructuring the funding model of PSBs with welfare resources.

\section{Fourth, PSB and PSM policy reforms are needed, as are related political and structural reforms}

In most of the cases discussed in this volume, state-administered broadcasters are tied to a barrage of red tape and colonial era regulations, made stricter in postcolonial times. Any progressive change, therefore, must be earned through significant policy reforms. However, media policy reform alone often achieves nothing in terms of practical change. For change to materialize it practice, media policy must be synchronized with wider political and structural reforms. The Audio-visual Communication Law in Morocco, for examples, assigns public service obligation to its state broadcasters. However, as Bouziane argues, the primary function of the law is to sustain the legitimacy of the monarch and to garner public consent to rule the media rather than to foster avenues for public service. This implies that changing political culture is key to changing media performance. 
Brambila brings out another important example from Latin American perspective, arguing that the right political, economic incentives, and policy reform measures can actually transform a propagandist state-broadcaster into a transparent, diverse, and financially independent public media (for instance, TVN in Chile). On a relevant note, proving Brambila's prediction correct, very recently (June 2016) seven Latin American countries - Chile, Uruguay, Peru, Mexico, Paraguay, Costa Rica, and Colombia - signed a joint agreement to create the first Public Television Network in Latin America (see, http://www.cntv.cl). The new network will promote the exchange between public channels on the topics of information, journalism, children's programs and other content, and will promote the creation of a joint pool of program. Such regional collaboration may prove to be exemplary for Asian and African public service and state-administered broadcasters.

\section{Fifth, the impact of digital switchover on public media varies across cases but it threatens the universal access characteristic of PSM, especially in low income countries}

The digital switchover marks the end of traditional broadcasting, therefore state-administered and public service broadcasters must cope with its consequences. While digital transition has opened new prospects for PSM (e.g. TV UNAM in Mexico) it has also created risk for local analog broadcasters whose equipment is becoming obsolete. Our study shows that the digital switchover jeopardizes a core characteristic of public service media: universal access. Low penetration of digital receivers appears to be a death penalty for universal access to PSM, and this is a significant challenge in countries with low per capita income. In Mexico only $21 \%$ of the population, mostly urbanites with middle incomes, have access to digital TV. In Bangladesh, the digitization of terrestrial broadcasting, similar to the problems faced by Prasar Bharati in India, will primarily benefit the private TV channels with urban and suburban middle-class audiences. Millions of poor rural residents, who truly represent the majority of citizens in the Global South, will not be able to afford the digital receiver to access public media.

While in a digitally converged media environment, multiplatform content distribution can provide more and improved access to content and increase efficiency in engaging specific audiences, it can also raise multiple risks and uncertainties (Aslama \& Syvertsen, 2007, p. 175). Gongxeka asserts that the need for additional capital to fund digitalization has led the South African PSB into a situation where they are directly competing with the commercial sector for capital as well as for audiences. This also changes the public service orientation of the PSB operator as digitalization causes more audience fragmentations, resulting in tighter commercial orientation for survival.

\section{Sixth, state-administered broadcasters are not lost causes}

Some of the findings in this volume suggest that state-administered broadcasters are not failing to provide public service media to the degree that some think. Mexico stands out for its vast network of government operated and university initiated terrestrial TV stations with cultural interests that continue to serve local publics. Bangladesh Television (BTV) and Bangladesh Betar are internationally famed for their documentaries and programs to create 
public awareness on agricultural prospects, environmental disasters, family planning, maternity health, child trafficking, and HIV/AIDS issues. One interesting feature of Taiwanese PSM is the creation of citizen journalism based video portal PeoPo where ordinary citizens were trained by the broadcaster to contribute their own video programs.

The state-administered broadcasters in Bangladesh, Morocco, South Africa, and Malaysia can learn from experiences of Mexican and Taiwanese public media initiatives and from many other PSM innovations exists around the world. A more comprehensive research is needed to explore such innovations. But one point that is key in this finding is the extent to which public support, that is to say grassroots popular support, is a critical success factor. Where PSM development has been most successful is precisely where popular support has been more persistent. This leads us to the seventh and last finding:

\section{Seventh, nongovernment and community initiatives are the future of PSM in supporting democratic development in the Global South}

Publicly or community funded nongovernment media initiatives (most notably, community radio) are emerging with new constituent possibilities. Web-based media projects make various locales of the global South living laboratories of protest and democratic development. Shahbag Movement in Bangladesh, for instance, was initiated by the bloggers. Around the same time, multiplatform initiatives (such as web and mobile content strategies of BBC Media Action) have gained considerable visibility and popularity as proxy public media in South Asia. A range of online tools such as QQ, Weblog, online forum, vlog, Weibo, and WeChat have been used by the workers in China to create and to circulate 'worker-generated content (WGC)' during times of industrial strikes (Qui, 2016). Media scholars need to respond and redefine the notion of public media in the light of these ecological changes in the media systems.

While state-administered and public broadcasters alike seem well able to support domestic cultural life and interests, democracy is a more complicated and challenging dimension. There, it remains rather doubtful as to the degree that formal institutional arrangements that are steeped in an authoritarian heritage of media control are able to break free, or actually allowed to break free, to a degree that can facilitate robust, persistent and continuous democratic development. More research is certainly needed to investigate de facto public service in media.

\section{Conclusion}

We have to stop thinking of public broadcasting as a stand-alone organization and see it as the principal mode in an emerging network of public and civil initiatives that, taken together, provide the basis for new shared cultural space, a digital commons, that can help forge new communal connections and stand against the continual pressure for enclosure coming from commercial interests on the one and the new moral essentialism on the other. (Graham Murdock, 2005, p. 213-214) 
No media operates in isolation from the politics and economy of the state. This is especially so for the public service media, precisely because it is 'public'. In the UK and to a lesser extent, Canada, left-wing labor movements have cultivated a social democratic political culture, and helped to instill, maintain, and enhance public service broadcasting traditions (Hackett \& Carroll, 2006, p. 200). Unfortunately, in the countries we have surveyed here, these is no clear indication of a vigorous leftist or progressive movement demanding, much less actively working, to liberate public broadcasters from the enclosures of the state or the market. The academicians, researchers, and the practitioners of the Global South should step forward to fill in the gap and be far more vocal in vigorously advocating a about major overhauling the public communication systems in the most of the world, which will contribute to the creation of alternative avenues and discourses of PSM provision.

The familiar complaints about a lack of funding and political corruption and control suggest that a decentralized, locally financed, self-managed, and community-operated public media system is likely to have a far better chance to survive and to flourish with limited resources and low tech set-ups than any attempt to replicate systems in the Global North. The Bolivian miners' radio may offer an exemplary case of such community-operated participatory public media initiative. Despite the repeated shutting down of the radio stations by oppressive military regimes and the miners' tenacious struggle for their restoration is a historic testament of social movements of decentralized means of communication, democratically organized at the grassroots level, with limited economic and technological resources (Bresnahan, 2007).

Perhaps we need less of a large broadcasters with a single public sphere and more smaller broadcasters serving a multitude of public sphericules with a variety of public media. It is clear that public media scholars and practitioners need to promote mutual dialogues and an intensification of collaborations of media initiatives particularly on a South-to-South basis, as well as South to North. The RIPE international initiative for the development of public service in media, and the Global PSM Experts Networks affiliated with that as well as the EBU and OSF offer a promising platform of goodwill efforts with practical features to enact dialogue, encourage debate, and conduct collaboration. We enthusiastically invite you to join the discussion and contribute your own unique perspectives and insights.

\section{Acknowledgement}

This volume is a result of collaboration and patient good work of many people. I would like to especially thank Professor Gregory Ferrell Lowe (University of Tampere) for reviewing and editing each chapter in this volume, and providing extensive support to manage this project. I am grateful to Dr. Minna Aslama Horowitz (St. John's University) whose feedback was instrumental in developing the Framework for Research that grounded this project. I am indebted to the intellectual and scholarly motivations provided by my doctoral advisors at SFU School of Communication, Professor Yuezhi Zhao, Professor Robert Hackett, and Professor Robert Anderson. Special thanks to the helpful and competent staff of SFU Library (Kevin Stranack, Sylvia Roberts, and Robyn Schafer) for making it possible to publish this work as an open access electronic book. Byron Hauck (SFU School of Communication) generously volunteered to edit some sections of this volume. Thanks to Mauve Pagé (Publishing@SFU) and Artemisa Bega (SFU School of Communication) for their assistance with designing the book. Finally, thanks to Open Society Foundations (OSF), especially Marius Dragomir and Sameer Padania, for supporting this publication through a generous grant that was administered by RIPE. 


\section{References}

Abbott, S. (2016). Rethinking public service broadcasting's place in international media development. Washington DC: Center for International Media Assistance. Retrieved from http://www.cima.ned.org/wpcontent/uploads/2016/02/CIMA 2016 Public Service Broadcasting.pdf

Aslama, M., \& Syvertsen, T. (2007). Public service broadcasting and new technologies: Marginalisation or re-monopolisation? In E. D. Bens (Ed.), Media between culture and commerce (pp. 167-178). Chicago, IL: Intellect Books.

Bresnahan, R. (2007). [Review of the book Community Radio in Bolivia: The Miners' Radio Stations, by A. O'Connor (Ed.)]. The Americas, 4, 672-673.

Curran, J. (2002). Media and power. London: Routledge.

Freedman, D. (2015). The resilience of TV and its implications for media policy. In K. Oakley \& J. O'Connor (Eds.). The Routledge companion to the cultural industries (pp. 120-129). London: Routledge.

Global South Studies Centre (2015). Introduction: Concepts of the global South. Retrieved from http://gssc.uni-koeln.de/

Hackett, R. A., \& W. K. Carroll (2006). Remaking media: The struggle to democratize public communication. London: Routledge.

Horowitz, M. A., \& Car, V. (Eds.) (2015). The future of public service media: New perspectives on public service media special issue. Medijske Studije/Media Studies, 6 (2015) 1. Retrieved from http://www.mediastudies.fpzg.hr/images/50022061/ms\%20vol6\%20br12\%20FINAL.pdf

Horowitz, M. A., \& Nieminen, H. (2016). Communication rights and public service media. Changing ecosystems, changing 'publicness'. In U. Carlsson (Ed.), Freedom of expression and media in transition: Studies and reflections in the digital age (pp. 27-32). Göteborg: NORDICOM.

Lowe, G. F., \& Bardoel, J. (Eds.) (2007). From public service broadcasting to public service media. RIPE@2007. Göteborg, Sweden: NORDICOM.

Lowe, G. F., \& Berg, C. E. (2013). The funding of public service media: A matter of value and values. The International Journal on Media Management, 15(2), 77-97.

Lowe, G. F., \& Martin, F. (Eds.) (2014). The values of public service media. RIPE@2013. Göteborg, Sweden: NORDICOM.

Lowe, G. F., \& Steemers, J. (Eds.) (2012). Regaining the initiative for public service media. RIPE@2011. Göteborg, Sweden: NORDICOM.

Lowe, G. F., \& Yamamoto, N. (Eds.) (2016). Crossing borders and boundaries in public service media.RIPE@2015. Göteborg, Sweden: NORDICOM.

Murdock, G. (2005). Building the digital commons: Public broadcasting in the age of the internet. In G. F. Lowe \& P. Jauert (Eds.), Cultural dilemmas in public service broadcasting (pp. 213230). Göteborg: NORDICOM.

Open Society Foundations (2013). Mapping digital media: Journalism, democracy and values. Retrieved from https://www.opensocietyfoundations.org/sites/default/files/mapping-digitalmedia-research-template-20130418.pdf

Qiu, J. (2016). Social media on the picket line. Media, Culture \& Society, 38(4), 619-633. 
Rahman, A. (2014). The problems with reimagining public media in the context of global South. Stream: Culture/Politics/Technology, 6(1), 56-65. Retrieved from http://journals.sfu.ca/stream/index.php/stream/article/viewArticle/88

Rigg, J. (2007). An everyday geography of the global South. New York, NY: Routledge.

Tambini, D. (2015). Five theses on public media and digitization: From a 56-country study. International Journal of Communication, 9, 1400-1424.

UNESCO (2014). Public service broadcasting (accessed December 21, 2013). Retrieved from: http://www.unesco.org/new/en/communication-and-information/mediadevelopment/public-service-broadcasting/

United Nation Development Program (2013). South-South cooperation. Retrieved from http://ssc.undp.org/content/dam/ssc/documents/exhibition triangular/SSCExPoster1.pdf

Zhao, Y. (2004). The state, the market, and media control in China. In P. Thomas (Ed.), Who owns the media? Global trends and local resistances (pp. 179-212). London: Zed Books. 


\section{Annex: PSM Initiatives in Non-Western Contexts: Framework for Research}

Key research questions: The researchers will primarily explore answers to two key questions:

1) What are the common dilemmas and biggest hurdles for PSM to function in a non-Western and emerging contexts?

2) What interventions may help the PSM cause? What is being done already, institutionally and in practice? What can they learn from each other?

The following framework can be adopted to answer to the above mentioned questions.

\section{Sections:}

A. History and background

B. Organization and structure

C. Transition from PSB to PSM

D. Critical Issues of PSM

E. Assessment and applied recommendations

\section{Subsections}

\section{A. History and background}

a. Overview of media industry, market, and audience share, and comparative regional data

i. Number of media outlets and platforms

ii. Viewership/readership/online users

iii. Media consumption habits and preferences

b. Major transformations and growth of media

c. Development of PSB/PSM - most significant turning points and emerging factors

d. Absence or presence of public service provisions, mandates, and obligations

i. in formal legal, policy, or constitutional forms

ii. as informal norms or practices

\section{B. Organization and structure}

a. Media outlets (channels, numbers, centers, etc.)

b. Ownership structures (state-administered, independent/autonomous, semi-autonomous)

c. Relevant regulatory bodies and authorities (ministry, commissions, divisions, offices)

d. Funding models (tax, subsidy, license fee, subscription, or public-private partnership etc.)

e. Business models (advertising, sponsorship, branding, quota, mandatory airing provisions)

\section{Transition from PSB to PSM}

a. State of digitization and convergence broadcasting and telecommunications

b. Varieties of digital media, content delivery models, and consumption patterns

c. Prospects of new media based delivery of public service contents

d. State of digital divide and its impact on media diversity

e. State of digital switchover and its impact on present and future of PSM

\section{Critical Issues of PSM}


a. Political and commercial influence on broadcasting, self-censorship, exploitations, etc.

b. Strengths and weaknesses of production and programming, primarily news services

c. Quality of news production and values of journalism (public versus market imperatives)

d. Audiences of PSM, inclusions and exclusions, dominant and marginalized

e. Linguistic and cultural diversity of content, censorship, extreme measures

f. Potentials of PSM initiatives to engage multiple publics and foster public avenues,

g. PSM initiatives by government and local and international NGOs, examples of best (successful) and failed (if there is any) public media experience in your region

h. Independence of PSM: policy issues surrounding broadcast and digital media

i. Pluralism of voices: existence of PSM community/network/activism

j. Importance of PSM reform movement and advocacy - presence, absence, visible impact

E. Assessment and recommendations

a. Summary of the main issues

i. Key challenges of PSM to grow or to function in the specific country context

ii. The most common hurdles faced across the countries within a region

iii. Values of existing PSM practices/initiatives

iv. Opportunities to grow and to strengthen

b. Policy recommendations: Suggestions for required policy intervention or policy reform

c. Suggestions for socio-political reform:

i. Suggestions for short term and long term practical initiatives to nurture and strengthen public service values

ii. Suggestions for priority for future PSM researchers

d. Normative assessment:

i. Contribution to global view pf PSM based on specific local knowledge (what can other regions learn from this context)

ii. Need to revise the traditional view/theory or understanding of PSM

iii. Minimum requirements for PSM that can be applicable elsewhere

e. Conclusion

Note: This is a simplified and tentative framework for further comparative research based on the research guideline presented here. It is a pilot framework and will be revised and improved as the research goes on. It does not claim to be complete, nor does it claim to be universally applicable.

* Anis Rahman, School of Communication, Simon Fraser University, 8888 University Drive, Burnaby, BC V5A 1S6, Canada. Email: abur@sfu.ca

Copyright (C) 2016 (Anis Rahman)

A. Rahman \& G. F. Lowe (Eds.), Public Service Media Initiatives in the Global South

Licensed under the Creative Commons Attribution-NonCommercial-NoDerivatives 4.0

International License (CC BY-NC-ND 4.0)

Available at http://monographs.lib.sfu.ca

DOI: 10.21810/sfulibrary.1.6 